Systematic Review Article

\title{
Efficacy of clear aligners in controlling orthodontic tooth movement A systematic review
}

\author{
Gabriele Rossinia; Simone Parrinia; Tommaso Castroflorio ${ }^{\mathrm{b}}$; Andrea Deregibus ${ }^{\mathrm{c}}$; \\ Cesare L. Debernardi ${ }^{\mathrm{d}}$
}

\begin{abstract}
Objective: To assess the scientific evidence related to the efficacy of clear aligner treatment (CAT) in controlling orthodontic tooth movement.

Materials and Methods: PubMed, PMC, NLM, Embase, Cochrane Central Register of Controlled Clinical Trials, Web of Knowledge, Scopus, Google Scholar, and LILACs were searched from January 2000 to June 2014 to identify all peer-reviewed articles potentially relevant to the review. Methodological shortcomings were highlighted and the quality of the studies was ranked using the Cochrane Tool for Risk of Bias Assessment.

Results: Eleven relevant articles were selected (two Randomized Clinical Trials (RCT), five prospective non-randomized, four retrospective non-randomized), and the risk of bias was moderate for six studies and unclear for the others. The amount of mean intrusion reported was $0.72 \mathrm{~mm}$. Extrusion was the most difficult movement to control ( $30 \%$ of accuracy), followed by rotation. Upper molar distalization revealed the highest predictability (88\%) when a bodily movement of at least $1.5 \mathrm{~mm}$ was prescribed. A decrease of the Little's Index (mandibular arch: $5 \mathrm{~mm}$; maxillary arch: $4 \mathrm{~mm}$ ) was observed in aligning arches.

Conclusions: CAT aligns and levels the arches; it is effective in controlling anterior intrusion but not anterior extrusion; it is effective in controlling posterior buccolingual inclination but not anterior buccolingual inclination; it is effective in controlling upper molar bodily movements of about $1.5 \mathrm{~mm}$; and it is not effective in controlling rotation of rounded teeth in particular. However, the results of this review should be interpreted with caution because of the number, quality, and heterogeneity of the studies. (Angle Orthod. 0000;00:000-000.)
\end{abstract}

KEY WORDS: Orthodontics; Clear aligner therapy; Invisible orthodontics; Invisalign ${ }^{\circledR}$

\section{INTRODUCTION}

In recent years, increasing numbers of adult patients have sought orthodontic treatment ${ }^{1}$ and expressed a desire for esthetic and comfortable alternatives to

\footnotetext{
a Resident, Department of Orthodontics, Dental School, University of Turin, Turin, Italy.

b Visiting Professor, Department of Orthodontics, Dental School, University of Turin, Turin, Italy.

${ }^{c}$ Adjunct Professor, Department of Orthodontics, Dental School, University of Turin, Turin, Italy.

d Professor and Department Chairman, Department of Orthodontics, Dental School, University of Turin, Turin, Italy.

Corresponding author: Dr Gabriele Rossini, Orthodontic Resident, Department of Orthodontics, Dental School, University of Turin, Via Nizza 230, Turin, Italy

(e-mail: dr.gabriele.rossini@gmail.com)
}

Accepted: September 2014. Submitted: June 2014.

Published Online: November 20, 2014

(c) 0000 by The EH Angle Education and Research Foundation, Inc.

DOI: $10.2319 / 061614-436.1$ conventional fixed appliances. ${ }^{2}$ The possibility of using clear overlay orthodontic appliances was introduced in 1946, when Kesling ${ }^{3}$ devised the concept of using a series of thermoplastic tooth positioners to progressively move misaligned teeth to improved positions. In 1997, Align Technology@ (Santa Clara, Calif) adapted and incorporated modern technologies to introduce the clear aligner treatment (CAT) as we know it, rendering Kesling's concept a feasible orthodontic treatment option. Although CAT has been cited as a safe, esthetic, and comfortable orthodontic procedure for adult patients, only a few investigations ${ }^{4,5}$ have focused on the predictability of orthodontic tooth movement (OTM). In 2005 Lagravère and Flores-Mir ${ }^{6}$ published a review in which only two studies met their inclusion criteria related to Invisalign therapy efficacy. The authors stated that no strong conclusions could be made regarding the treatment effects of this kind of orthodontic treatment. Thus, clinicians who plan to use CAT on their patients have to rely on their clinical 
Table 1. Search Strategy

\begin{tabular}{|c|c|}
\hline Database & Search Strategy \\
\hline PubMed, PMC, Scopus, Web of Knowledge, Embase, NLM & $\begin{array}{l}\text { ((Orthodont* OR Clear) aligner }{ }^{\star} \text { OR Invisalign) and (effect* OR effic }{ }^{\star} \text { OR } \\
\left.\text { outcom }^{\star} \text { OR advant }{ }^{\star}\right)\end{array}$ \\
\hline LILACs & $\begin{array}{l}\text { ((Orthodont\$ OR Clear) aligner\$ OR Invisalign) and (effect\$ OR effic\$ OR } \\
\text { outcom\$ OR advent\$) }\end{array}$ \\
\hline Cochrane Central Register of Controlled Clinical Trials & $\begin{array}{l}\text { (Orthodontic aligner }{ }^{*} \text { or clear aligner }{ }^{*} \text { or Invisalign) and (effect }{ }^{\star} \text { or effic }{ }^{*} \text { or } \\
\text { outcom }^{*} \text { or advant }{ }^{\star} \text { ) }\end{array}$ \\
\hline
\end{tabular}

experience, the opinions of experts, and limited published evidence. ${ }^{6}$

The present systematic review was undertaken to update the knowledge of the available evidence about CAT and to answer the following clinical research question: "Is CAT effective in controlling the orthodontic movement in non-growing subjects?"

\section{MATERIALS AND METHODS}

On June 15, 2014, a systematic search in the medical literature produced between January 2000 and June 2014 was performed to identify all peerreviewed articles potentially relevant to the review's question. In order to retrieve lists of potential articles to be included in the review, the search strategy illustrated in Table 1 was used in the following databases:

- PubMed

- PubMed Central

- National Library of Medicine's Medline

- Embase

- Cochrane Central Register of Controlled Clinical Trials

- Web of Knowledge

- Scopus

- Google Scholar

- LILACs

A manual search was thoroughly performed to identify additional articles in the medical library of Turin University, in the authors' personal libraries, and in the references of selected articles. International patents, abstracts, and presentations from international orthodontic meetings were also evaluated. Title and abstract screening was performed to select articles for full text retrieval.

The inclusion and exclusion criteria for admittance in the systematic review are reported in Table 2.

The reference lists of these articles were perused, and references related to the articles were followed up. Duplicate articles were removed, and the studies were selected for inclusion independently by two of the authors. Disagreements were resolved through discussion between all of the authors.

The 'PICOS' approach was used independently and in duplicate by two review authors to extract data from the selected articles. PICOS stands for "population (participants), intervention (or exposure for observational studies), comparator, outcomes and study design" (Table 3).

The outcome for this study was the efficacy of CAT in performing intrusion, extrusion, rotation, tipping, and alignment movements. According to the Centre for Reviews and Dissemination, University of York (CRD) ${ }^{7}$ and to the Preferred Reporting Items for Systematic Reviews and Meta-Analyses (PRISMA) ${ }^{8}$ statements, evaluation of methodological quality gives an indication of the strength of evidence provided by the study because flaws in the design or in the conduction of a study can result in biases. A grading system described by the Swedish Council on Technology Assessment in Health Care (SBU) and the CRD was used to rate the methodological quality of the articles and to assess the level of evidence for the conclusions of this review (Tables 4-6). ${ }^{7,9}$

Table 2. Study Selection Criteria

\begin{tabular}{ll}
\hline \multicolumn{1}{c}{ Inclusion Criteria } & \multicolumn{1}{c}{ Exclusion Criteria } \\
\hline $\begin{array}{l}\text { Prospective and retrospective original studies on human subjects } \\
\text { with permanent dentition (minimum chronological age of } 15 \mathrm{y})\end{array}$ & $\begin{array}{l}\text { Studies on patients with genetic syndrome and severe facial } \\
\text { malformations } \\
\text { Studies on orthodontic treatment with clear aligners }\end{array}$ \\
$\begin{array}{ll}\text { Studies that included clear descriptions of the materials and } \\
\text { applied technique }\end{array}$ & $\begin{array}{l}\text { Case reports } \\
\text { Studies with adequate statistical analysis }\end{array}$ \\
& $\begin{array}{l}\text { Reviews } \\
\text { Abstracts }\end{array}$ \\
& $\begin{array}{l}\text { Author debates } \\
\text { Summary articles }\end{array}$ \\
& Studies with fewer than 10 patients \\
& Studies on animals \\
\hline
\end{tabular}


Table 3. PICOS Table

\begin{tabular}{|c|c|c|c|c|c|}
\hline Author, Year & Study Design & Population & Intervention & Comparison & $\begin{array}{c}\text { Outcomes } \\
\text { (Statistically Significant) }\end{array}$ \\
\hline $\begin{array}{l}\text { Clements et } \\
\text { al., } 2003^{17}\end{array}$ & Prospective RCT & $\begin{array}{l}51 \text { pts; } \\
\text { DI between } 10 \text { and } 20\end{array}$ & $\begin{array}{l}\text { Description of aligner } \\
\text { stiffness evaluated }\end{array}$ & $\begin{array}{l}\text { Pretreatment models, } \\
\text { different materials and } \\
\text { protocols }\end{array}$ & $\mathrm{PBI}=0.02(P=.0475)$ \\
\hline $\begin{array}{l}\text { Djeu et al., } \\
2005^{10}\end{array}$ & Retrospective study & $\begin{array}{l}96 \text { pts; } \\
\text { treatment duration: } \\
1.7 \text { y fixed appliance } \\
1.4 \text { y Invisalign }\end{array}$ & $\begin{array}{l}\text { OGS score of Invisalign } \\
\text { appliance treatment } \\
\text { outcomes }\end{array}$ & $\begin{array}{l}\text { OGS score of conven- } \\
\text { tional fixed appliance } \\
\text { treatment outcomes }\end{array}$ & $\begin{array}{l}\text { OGS score: } \\
\text { mean overall score }= \\
13.14 \text { (braces) } \\
\text { OVJ }=2.65 \\
\text { Buccolingual inclination } \\
=1.38 \\
\text { Occlusal contacts }=4.81 \\
\text { Occlusal relations }=2.21 \\
\text { Buccal posterior cross- } \\
\text { bite/OGS scores } \\
\text { correlation }=0.2849 \\
\text { Overjet/OGS scores } \\
\text { correlation }=0.3034 \\
\left.\text { (Invisalign }{ }^{\circledR}\right) ; 0.2975 \\
\text { (braces) } \\
\text { Occlusion/OGS scores } \\
\text { correlation }=0.5288 \\
\text { (Invisalign); } 0.4497 \\
\text { (braces) } \\
\text { OGS passing rate }= \\
13 \text { (braces) }\end{array}$ \\
\hline $\begin{array}{l}\text { Kuncio et al., } \\
2007^{14}\end{array}$ & Prospective study & 22 pts (20 F, 2 M) & $\begin{array}{l}\text { Postretention OGS } \\
\text { score after Invisalign } \\
\text { treatment }\end{array}$ & $\begin{array}{l}\text { Postretention OGS } \\
\text { score after fixed ap- } \\
\text { pliance treatment }\end{array}$ & $\begin{array}{l}\text { Total alignment } \\
\text { Mdb anterior alignment }\end{array}$ \\
\hline $\begin{array}{l}\text { Baldwin et al., } \\
2008^{18}\end{array}$ & Prospective RCT & 24 pts (18 F, $6 \mathrm{M})$ & $\begin{array}{l}\text { Measurement of tooth } \\
\text { tipping adjacent to } \\
\text { premolar extraction } \\
\text { spaces }\end{array}$ & $\begin{array}{l}\text { Movement of teeth adja- } \\
\text { cent to premolar ex- } \\
\text { traction sites during } \\
\text { space closure with } \\
\text { fixed appliances }\end{array}$ & $\begin{array}{l}\text { Tooth tipping } \\
\text { Interdental angle }=17.3\end{array}$ \\
\hline $\begin{array}{l}\text { Kravitz et al., } \\
2008^{13}\end{array}$ & Prospective study & $\begin{array}{l}31 \text { pts }(18 \mathrm{~F}, 13 \mathrm{M}) \text {; } \\
\text { treatment duration: } \\
\quad 7 \text { mo }\end{array}$ & $\begin{array}{l}\text { Quantitative measure- } \\
\text { ments for the predict- } \\
\text { ed and achieved ca- } \\
\text { nine rotation }\end{array}$ & $\begin{array}{l}\text { Movement predictions } \\
\text { made by ClinCheck@ }\end{array}$ & $\begin{array}{l}\text { No statistically significant } \\
\text { outcomes }\end{array}$ \\
\hline $\begin{array}{l}\text { Kravitz et al., } \\
2009^{4}\end{array}$ & Prospective study & $\begin{array}{l}37 \text { pts }(23 \mathrm{~F}, 13 \mathrm{M}) \text {; } \\
\text { mean age: } 31 \mathrm{y} ; \\
\text { treatment duration: } \\
10 \text { aligner } \mathrm{mx} \\
12 \text { aligner } \mathrm{mdb}\end{array}$ & $\begin{array}{l}\text { Quantitative measure- } \\
\text { ments for the predict- } \\
\text { ed and achieved } \\
\text { movements in the } \\
\text { anterior region }\end{array}$ & $\begin{array}{l}\text { Movement predictions } \\
\text { made by ClinCheck@ }\end{array}$ & $\begin{array}{l}\text { Canine rotation accuracy }= \\
32.2 \%(\mathrm{Mx}) ; 29.1 \% \\
(\mathrm{Mdb})\end{array}$ \\
\hline $\begin{array}{l}\text { Pavoni et al., } \\
2011^{15}\end{array}$ & Prospective study & $\begin{array}{l}60 \text { pts: } \\
40 \text { self-ligating fixed } \\
\text { appliance } \\
20 \text { Invisalign; } \\
\text { Class I malocclusion, } \\
\text { mild crowding in Mdb } \\
\text { arch; } \\
\text { treatment duration: } \\
18 \pm 2 \text { mo }\end{array}$ & $\begin{array}{l}\text { Measurements made } \\
\text { on the maxillary den- } \\
\text { tal casts at the be- } \\
\text { ginning and at the } \\
\text { completion of Invis- } \\
\text { align treatment }\end{array}$ & $\begin{array}{l}\text { Outcomes of self-ligating } \\
\text { treatment }\end{array}$ & $\begin{array}{l}\text { Invisalign T0/T1 }(\mathrm{mm}): \\
\text { SPWF }=0.45 \\
\text { MWF }=0.5 \\
\text { Self-ligating/Invisalign }(\mathrm{mm}) \text { : } \\
\text { CWCDD }=2.65 \\
\text { FPWFDD }=3.35 \\
\text { FPWLDD }=2.30 \\
\text { SPWFDD }=2.05 \\
\text { SPWLDD }=1.85 \\
\text { APDD }=1.35\end{array}$ \\
\hline $\begin{array}{l}\text { Drake et al., } \\
2012^{16}\end{array}$ & Prospective study & $\begin{array}{l}52 \text { pts: } \\
151 \mathrm{wk} \\
372 \mathrm{wk} ; \\
\text { treatment duration: } \\
\quad 8 \mathrm{wk}\end{array}$ & $\begin{array}{l}\text { Examination of influ- } \\
\text { ence on tooth move- } \\
\text { ment by material and } \\
\text { subject-specific fac- } \\
\text { tors }\end{array}$ & $\begin{array}{l}37 \text { Subjects who partici- } \\
\text { pated in another study } \\
\text { (biweekly control } \\
\text { group); CBCT images } \\
\text { and data from a similar } \\
\text { protocol }\end{array}$ & OTM first week = 0.22 \\
\hline $\begin{array}{l}\text { Krieger et al., } \\
2012^{5}\end{array}$ & Retrospective study & $\begin{array}{l}50 \text { pts }(34 \mathrm{~F}, 16 \mathrm{M}) ; \\
\text { low to moderate } \\
\quad \mathrm{Mx} \text { and/or } \mathrm{Mdb} \\
\text { crowding; } \\
\text { mean age: } 33 \pm 11.19 \mathrm{y}\end{array}$ & $\begin{array}{l}\text { Superimposition of ini- } \\
\text { tial and final casts of } \\
\text { Invisalign treatment }\end{array}$ & $\begin{array}{l}\text { Treatment starting point } \\
\text { and predicted move- } \\
\text { ment made with Clin- } \\
\text { Check@ }\end{array}$ & OVB $[\mathrm{Cl},-1.02,-.39]$ \\
\hline
\end{tabular}


Table 3. Continued.

\begin{tabular}{|c|c|c|c|c|c|}
\hline Author, Year & Study Design & Population & Intervention & Comparison & $\begin{array}{c}\text { Outcomes } \\
\text { (Statistically Significant) }\end{array}$ \\
\hline $\begin{array}{l}\text { Kassas et al., } \\
2013^{11}\end{array}$ & Retrospective study & $\begin{array}{l}31 \mathrm{pts}(20 \mathrm{~F}, 11 \mathrm{M}) \\
\text { treatment duration: } \\
18 \pm 5 \mathrm{mo}\end{array}$ & $\begin{array}{l}\text { MGS score of pre- and } \\
\text { posttreatment models }\end{array}$ & $\begin{array}{l}\text { Cases served as their } \\
\text { own controls }\end{array}$ & $\begin{array}{l}\text { MGS scores: } \\
\text { Alignment }=9.16 \\
\text { Buccolingual inclination } \\
\quad=0.74 \\
\text { Total MGS score }=9.16\end{array}$ \\
\hline $\begin{array}{l}\text { Simon et al., } \\
2014^{12}\end{array}$ & Retrospective study & $\begin{array}{l}30 \mathrm{pts} ; \\
11 \mathrm{M} ; 19 \mathrm{~F} ; \\
\text { age: } 13-72 \mathrm{y} ; \\
\text { mean age: } 32.9 \text { y }\end{array}$ & $\begin{array}{l}\text { Superimposition of ini- } \\
\text { tial and final digital } \\
\text { casts of Invisalign } \\
\text { treatment }\end{array}$ & $\begin{array}{l}\text { Treatment starting point } \\
\text { and predicted move- } \\
\text { ment made with Clin- } \\
\text { Check@ }\end{array}$ & $\begin{array}{l}\text { T2/Clin T2 }(P<.05): \\
\text { Premolar derotation with } \\
\text { attachments } \\
\text { Premolar derotation } \\
\text { without attachments } \\
\text { Incisor torque with } \\
\text { attachments } \\
\text { Incisor torque with PR }\end{array}$ \\
\hline
\end{tabular}

a PICOS indicates "population (participants), intervention (or exposure for observational studies), comparator, outcomes and study design"; pts, patients; DI, discrepancy index; PBI, papillary bleeding index; OGS, objective grading system; OVJ, overjet; SPWF, second premolar width (fossa); MWF, molar width (fossa); CWCDD, intercanine width (cuspal) mean difference; FPWFDD, first interpremolar width (fossa) mean difference; FPWLDD, first interpremolar width (lingual) mean difference; SPWFDD, second interpremolar width (fossa) mean difference; SPWLDD, second interpremolar width (lingual) mean difference; APDD, arch perimeter mean difference; OTM, overall tooth movement; OVB, overbite; MGS, model grading system; T2, clinically achieved tooth movement; CBCT, cone beam computed tomography; CLIN T2, tooth movement predicted by ClinCheck; and PR, power ridge.

\section{RESULTS}

Eleven relevant publications were identified: four studies $^{5,10-12}$ were retrospective non-randomized, five studies ${ }^{4,13-16}$ were prospective non-randomized, and two studies ${ }^{17,18}$ were prospective randomized. The article selection process is illustrated in the PRISMA Flow Diagram (Figure 1).

Sample size in individual studies ranged from 22 to 96 , with a total of 480 patients. Age at the start of aligner's treatment in the evaluated samples ranged from 13 to 72 years. The devices applied in the studies were Invisalign aligners.

Table 4. Swedish Council on Technology Assessment in Health Care (SBU) Criteria for Grading Assessed Studies

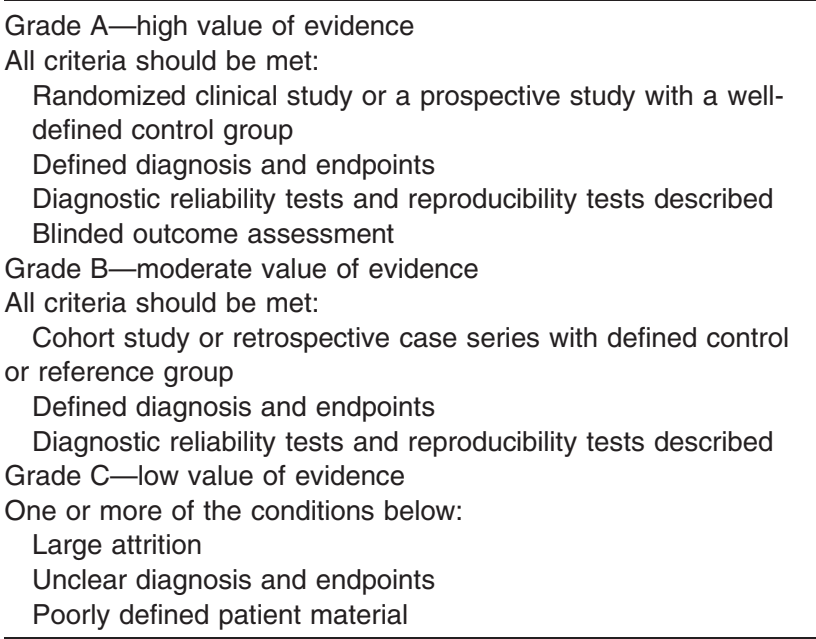

\section{Quality Analysis}

According to the SBU tool (Tables 4-6), among the selected sample, the methodological quality was moderate for six studies ${ }^{10,14-18}$ and limited for the others. ${ }^{4,5,11-13}$ Thus, conclusions with a limited level of evidence could be drawn from the review process. The most recurrent sources of bias were related to the study design, the sample size, and the lack of control group. Furthermore, other sources of bias were inadequate sequence generation (four studies), lack of allocation concealment (three studies), and lack of a proper blinding procedure (four studies).

\section{Effects of Interventions}

Intrusion. The superimposition of the virtual model of the predicted tooth position over the virtual model of the achieved tooth position was performed for 189 intruded teeth. ${ }^{4}$ The highest accuracy of intrusion was achieved by the maxillary (45\%) and mandibular $(47 \%)$ central incisors. The lowest accuracy of intrusion was achieved by the maxillary lateral incisors (33\%). The average amount of true intrusion attempted was $0.72 \mathrm{~mm}$.

Extrusion. Extrusion was the least accurate tooth movement achieved with CAT (30\% of predictability). ${ }^{4}$ The maxillary (18\%) and the mandibular $(25 \%)$ central incisors had the lowest accuracy. The average amount of extrusion attempted was $0.56 \mathrm{~mm}$. Two retrospective studies ${ }^{5,11}$ outlined that movements on the vertical plane resulted in larger deviations $(-0.71 \mathrm{~mm}$; standard deviation [SD] 0.87; confidence interval $[\mathrm{Cl}]$ $[-0.54,-0.15])$. 
Table 5. Definitions of Evidence Level

\begin{tabular}{cll}
\hline Level & Evidence & \multicolumn{1}{c}{ Definition } \\
\hline 1 & Strong & At least two studies assessed with level "A" \\
2 & Moderate & One study with level "A" and at least two studies with level "B" \\
3 & Limited & At least two studies with level "B" \\
4 & Inconclusive & Fewer than two studies with level "B" \\
\hline
\end{tabular}

A Randomized Clinical Trial ${ }^{17}$ conducted on a sample of 51 patients investigating the effects of time and material stiffness on the efficacy of CAT orthodontic movement revealed that aligners were successful in controlling vertical buccal occlusion (Peer Assessment Rating [PAR] score $=0$ ).

A retrospective study ${ }^{10}$ comparing two groups of 48 patients (CAT and braces treatment groups) revealed a similar average Orthodontics Objective Grading System (OGS) score for the alignment of marginal ridges in CAT $(-4.9)$ and braces $(-4.5)$ patients.

Rotation. A prospective study ${ }^{13}$ conducted on 53 canines of 31 subjects assessed a mean accuracy for canine rotation of $36 \%$. Canines that received interproximal reduction (IPR) reported the highest mean rotational accuracy and lowest standard deviation $(43 \%$; SD $=22.6 \%)$.

In Kravitz et al. ${ }^{4}$ the accuracy of rotation for maxillary canines was $32 \%$, lower than that of the maxillary central incisors $(55 \%)$ and mandibular lateral incisors $(52 \%)$. The least accuracy was detected for the mandibular canine $(29 \%)$. For rotations greater than $15^{\circ}$ the accuracy of maxillary canine movement was significantly reduced (19\%; SD $=14.1 \% ; P<.05$ ). Similar results were achieved by Simon et al., ${ }^{12}$ who demonstrated that staging (amount of rotation/aligner) also had a considerable impact on the treatment efficacy: for premolar rotations with a staging of $<1.5 \%$ aligner, the total efficacy was $41.8 \%(S D=0.3 \%)$, whereas with a staging of $>1.5 \%$ aligner, the accuracy decreased to $23 \%$ (SD $=0.2 \%$ ).

Mesiodistal tipping. Baldwin et al. ${ }^{18}$ showed a mean change in radiographic and dental cast interdental angle of about $17^{\circ}$ after CAT $(P<.0001)$. In their 2009

Table 6. Grading of Selected Studies

\begin{tabular}{|c|c|}
\hline Author, Year & Grade \\
\hline Clements et al., $2003^{17}$ & B \\
\hline Djeu et al., $2005^{10}$ & $\mathrm{~B}$ \\
\hline Kuncio et al., $2007^{14}$ & B \\
\hline Baldwin et al., $2008^{18}$ & B \\
\hline Kravitz et al., $2008^{13}$ & C \\
\hline Kravitz et al., $2009^{4}$ & $\mathrm{C}$ \\
\hline Pavoni et al., $2011^{15}$ & $\mathrm{~B}$ \\
\hline Drake et al., $2012^{16}$ & $\mathrm{~B}$ \\
\hline Krieger et al., $2012^{5}$ & $\mathrm{C}$ \\
\hline Kassas et al., $2013^{11}$ & $\mathrm{C}$ \\
\hline Simon et al., $2014^{12}$ & C \\
\hline
\end{tabular}

study on anterior teeth, Kravitz et al. ${ }^{4}$ showed a mean accuracy of $41 \%$ for mesiodistal tipping, in which the highest accuracy was achieved by the maxillary (43\%) and mandibular (49\%) lateral incisors. The maxillary (35\%) and mandibular (27\%) canines and the maxillary central incisors (39\%) had the lowest accuracy.

In 2005 Djeu et al. ${ }^{10}$ reported that CAT and fixed appliance treatment achieved similar OGS scores for root angulation at the end of treatment. In 2012, in their prospective study, Drake et al. ${ }^{16}$ reported that 4.4 times more OTM occurred during the first week than during the second week of aligner wear, considering all of the 2-week periods. Even if bodily protraction of the target tooth was programmed, it resulted in uncontrolled tipping. Simon et al. ${ }^{12}$ revealed a high predictability $(88 \%)$ of the distalization movement of upper molars (bodily movement) when the movement was supported by attachments.

Buccolingual tipping. Djeu et al. ${ }^{10}$ observed better scores for fixed appliances than for CAT in relation to buccolingual tipping (braces: -2.8 ; $\mathrm{SD}=2.6$; CAT: -4.2 ; $\mathrm{SD}=2.73 ; P<.05)$. However, in their 2013 retrospective study, Kassas et al. ${ }^{11}$ showed a significant improvement of the American Board of Orthodontics Model Grading System (MGS) score for buccolingual inclination, especially in the posterior region $(-0.74 ; P<.05)$. Kravitz et al. ${ }^{4}$ showed that lingual crown tip (53\%) was significantly more accurate than labial crown tip (38\%), particularly for maxillary incisors. Simon et al. ${ }^{12}$ showed no substantial differences if the upper central incisor torque was supported by a horizontal ellipsoid attachment (mean accuracy: $51.5 \%$; $S D=0.2 \%$ ) or by an altered aligner geometry (mean accuracy: $49 \%$; SD $=0.2 \%$ ).

Aligning (arch lengthening, lingual constriction, alignment scores). Clements et al. ${ }^{17}$ reported an improvement of the PAR score for anterior alignment of $78 \%$ of the analyzed sample, while $12 \%$ had no change, and only $10 \%$ worsened. Kuncio et al. ${ }^{14}$ found a statistically significant worsening in OGS score with regard to stability of total alignment after CAT compared to braces treatment after 3 years of retention $(-1.6 ; P<.05)$. Krieger et al. ${ }^{5}$ observed a decrease in the Little's Irregularity Index between preand post-treatment casts in maxillary $(-3.8 \mathrm{~mm})$ and mandibular $(-5 \mathrm{~mm})$ arches. A significant improvement of the OGS score for alignment $(-9 ;-P<.001)$ was reported by Kassas et al. ${ }^{11}$ 

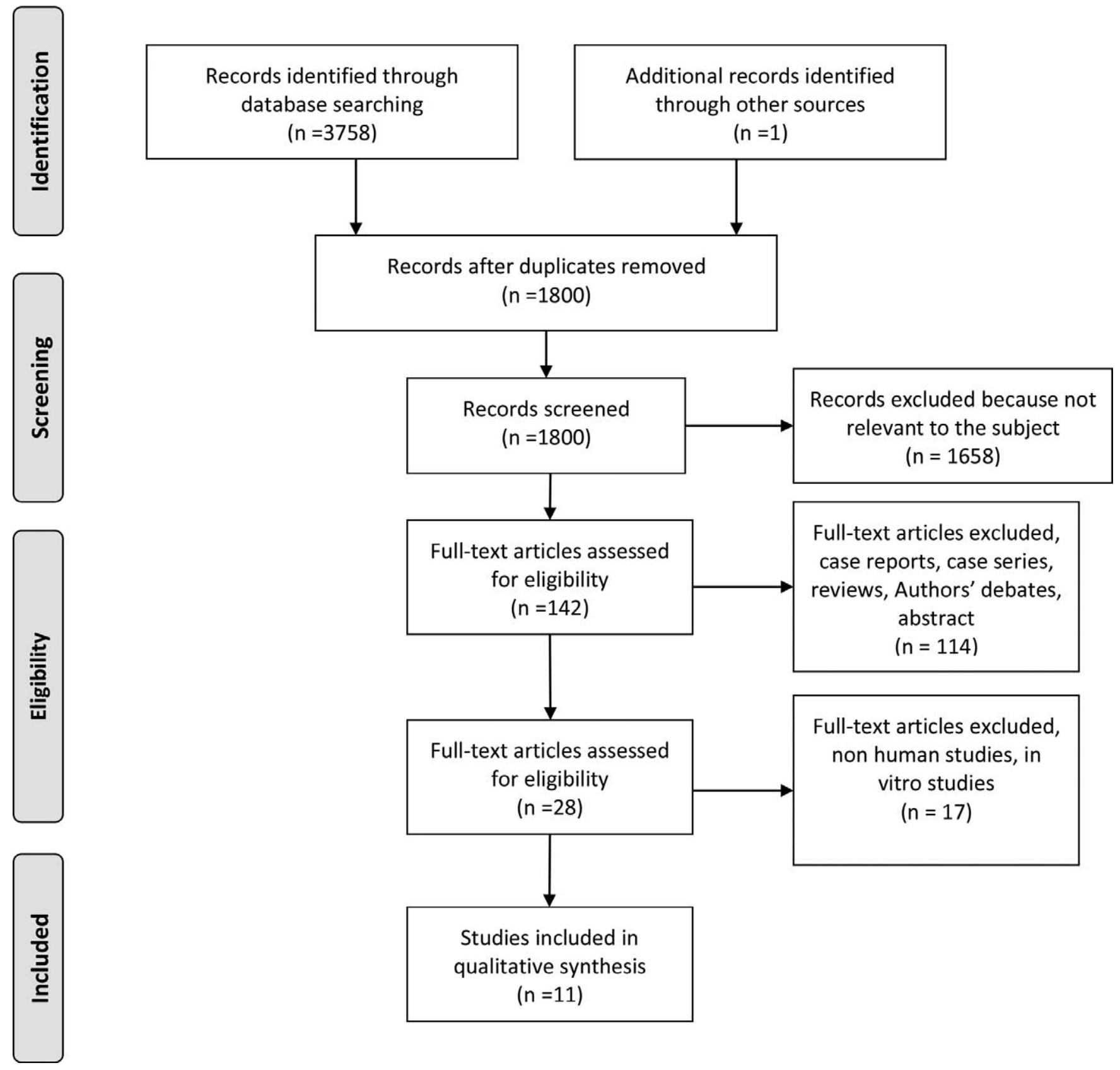

Figure 1. Flow chart according to the PRISMA Statement.

Pavoni et al. ${ }^{15}$ analyzed the arch expansion in posttreatment casts of CAT and self-ligating appliance patients. The CAT group showed a significant increase $(0.45 \mathrm{~mm})$ in second interpremolar width and in intermolar widths $(0.5 \mathrm{~mm})$ at the fossa points, with significant differences with respect to the self-ligating group.

\section{DISCUSSION}

The present systematic review showed that the use of aligners is recommended in simple malocclusions.
The methodology of the selected investigations was generally poor, with the majority of studies (63\%) presenting high risk of bias. Very strong limitations were the absence of proper control groups, the absence of proper blinding procedures, the lack of sample randomization procedures, and the small sample sizes. In two studies ${ }^{10,14}$ patients were treated by orthodontists with no experience with CAT, while in other studies ${ }^{10,11,14}$ the comparison between CAT and fixed orthodontics was based upon malocclusion scoring scales, such as the PAR index, which presents limitations, mainly related to the generic weighting system. 
This review identified only one study ${ }^{4}$ in which the intrusion of anterior teeth was investigated. For patients with vertical growth tendencies true incisor intrusion is the treatment of choice..$^{19}$ The average true intrusion obtained with $\mathrm{CAT}^{4}$ in non-growing subjects was comparable to the true intrusion obtained in a similar sample of a population with continuous arch technique but lower than the one reported for the segmented arch technique. ${ }^{20}$ Thus, CAT could be recommended for the treatment of simple malocclusions with light overbite discrepancies.

Open bite is a challenging malocclusion to treat, with a high incidence of relapse. ${ }^{21}$ Extrusion is the least accurate tooth movement to perform with CAT ${ }^{4}$ and it can result in larger deviations compared to other movements. ${ }^{5}$ This lack of efficiency could be due to the difficulty of the appliance in developing enough force to extrude teeth in a significant way. However, PAR and OGS scores revealed that aligners were as successful as fixed appliances in controlling vertical buccal occlusion, even years after the end of treatment. ${ }^{10,11,14,17}$ Thus, on the basis of the existing literature, CAT is not recommended to treat open bite.

Proffit et al. ${ }^{22}$ reported that forces required to produce rotation of a tooth around its long axis are similar to those required to produce tipping. This is due to the fact that the force could be distributed over the entire periodontal ligament rather than over a narrow vertical strip. It is thus impossible to apply a pure rotational force without a tipping movement of the tooth in its socket. Prospective studies ${ }^{4,13}$ revealed a generally low degree of control and predictability for rotations. Similar data were reported by Nguyen and Chen $^{23}$ : incisors achieved $60 \%$ of the predicted rotation, while canines and premolars had the lowest accuracy (39\%). Thus, teeth with rounded crowns seem to be more difficult to rotate with CAT. Furthermore, in 2008 Kravitz et al. ${ }^{13}$ stated that IPR influenced in a positive way the correction of rotations, while in 2005 Djeu et al. ${ }^{10}$ supported the use of attachments to improve the accuracy of this movement. In their retrospective study, Simon et al., ${ }^{12}$ analyzing premolar rotations of $>10^{\circ}$, concluded that the use of attachments and the amount of movement per aligner had a great impact on the treatment predictability; reducing the staging and using attachments increase the predictability of tooth movement.

Even if the evidence emerging for rotation control is not of good quality, it is always recommended to plan overcorrections, especially if rotations exceed $15^{\circ}$, to use attachments, and to reduce staging to less than $1.5^{\circ}$ per aligner.

The present review suggests that CAT can produce both uncontrolled and controlled tipping movements. The uncontrolled tipping in closing extraction sites ${ }^{18}$ and the scarce results in tipping canines ${ }^{4}$ suggest that teeth with larger roots might have greater difficulty achieving mesiodistal movements. However, in another study, ${ }^{10}$ CAT and fixed appliance treatment achieved similar OGS scores for root angulation at the end of treatment.

It is generally thought that aligners can easily tip crowns but cannot tip roots because of the lack of control of tooth movement. This conclusion is reinforced by Drake et al., ${ }^{16}$ who stated that bodily movement is not achievable with CAT. The analysis of the study underlined a fundamental error in the treatment planning: the prescribed staging in their sample was at least twice the maximum rate per aligner currently prescribed for patient treatment. Thus, it is possible that a greater percentage of the prescription should be achieved if the maximum 2week activation was decreased to $0.25 \mathrm{~mm}$ or less instead of $0.5 \mathrm{~mm}$. Thus, the experimental procedure did not reflect the daily clinical routine. On the contrary, Simon et al. ${ }^{12}$ reported a high accuracy $(88 \%)$ of the bodily movement of upper molars when a distalization movement of at least $1.5 \mathrm{~mm}$ was prescribed. The authors reported the best accuracy when the movement was supported by the presence of an attachment on the tooth surface. Furthermore, they underlined the importance of staging in the treatment predictability. The contrasting results reported in the analyzed literature regarding the CAT tipping control might be due to the difficulties related to the application of a couple of force with this kind of appliances. Altered aligner geometries and attachments seem to be required in order to improve the root control. ${ }^{12}$ Thus, well-designed RCTs are needed to clarify the real efficiency of CAT in moving crowns and root along the arch.

The results of one $\mathrm{RCT}^{17}$ and two retrospective studies $^{5,11}$ agree in assessing the efficacy of CAT in aligning and straightening the arches, with better results for mild to moderate crowding when compared to the results obtained with fixed appliances. Attention has to be paid to the level of relapse, which seems to be higher with respect to fixed appliances. ${ }^{14}$ It has been suggested that teeth moved with aligners did not undergo the typical stages of movement, ${ }^{14}$ as described by Krishnan and Davidovitch, ${ }^{24}$ because of the intermittent forces applied by the aligners. However, light continuous orthodontics forces seem to be perceived as intermittent by the periodontium, ${ }^{25}$ and orthodontic intermittent forces are able to produce OTM with less cell damage in the periodontium. ${ }^{26}$ Therefore, it is most likely the orthodontist, rather than the technique, that is responsible for such results.

In the considered articles the analyzed attachments were rectangular or ellipsoid attachments. All of the 
attachments improved the quality of the OTM. During the last 5 years a sharper biomechanical approach was introduced by Align Technology to obtain more effective attachment designs, pressure points, or pressure areas and aligner bends. Furthermore, in every study the percentage of OTM obtained with CAT was related to treatments concluded without a finishing or refinement phase.

Considering all the results of this systematic review it is recommended that future researchers in this field should include RCTs with rigorous methodology and proper sample size in order to increase the power of the studies for estimating the effects. Only with this knowledge will it be possible to develop defined CAT treatment protocols for daily clinical practice.

\section{CONCLUSIONS}

- Most of the studies presented with methodological problems: small sample size, bias and confounding variables, lack of method error analysis, blinding in measurements, and deficient or missing statistical methods. The quality level of the studies was not sufficient to draw any evidence-based conclusions.

- CAT is an effective procedure that is able to align and level the arches in non-growing subjects.

- The anterior intrusion movement achievable with CAT is comparable to that reported for the straight wire technique.

- CAT is not effective in controlling anterior extrusion movement. Contrasting results have been reported in relation to the posterior vertical control, and a definite conclusion cannot be drawn.

- CAT is not effective in controlling rotations, especially of rounded teeth.

- CAT is effective in controlling upper molar bodily movement when a distalization of $1.5 \mathrm{~mm}$ has been prescribed.

- CAT is not based on aligners alone. It requires the use of auxiliaries (attachments, interarch elastics, IPR, altered aligner geometries) to improve the predictability of orthodontic movement.

\section{REFERENCES}

1. Melsen B. Northcroft Lecture: how has the spectrum of orthodontics changed over the past decades? J Orthod. 2011;38:134-143.

2. Rosvall MD, Fields HW, Ziuchkovski J, Rosenstiel SF, Johnston WM. Attractiveness, acceptability, and value of orthodontic appliances. Am J Orthod Dentofacial Orthop. 2009;135:276.e1-276.e12; discussion 276-277.

3. Kesling HD. Coordinating the predetermined pattern and tooth positioner with conventional treatment. Am J Orthod Oral Surg. 1946;32:285-293.

4. Kravitz ND, Kusnoto B, Agran B, Viana G. How well does Invisalign work? A prospective clinical study evaluating the efficacy of tooth movement with Invisalign. Am J Orthod Dentofacial Orthop. 2009;35:27-35.

5. Krieger E, Seiferth J, Marinello I, et al. Invisalign ${ }^{\circledR}$ treatment in the anterior region: were the predicted tooth movements achieved? J Orofac Orthop. 2012;73:365-376.

6. Lagravère $\mathrm{MO}$, Flores-Mir $\mathrm{C}$. The treatment effects of Invisalign orthodontic aligners: a systematic review. J Am Dent Assoc. 2005;136:1724-1729.

7. Centre for Reviews and Dissemination, University of York, Systematic Reviews-CRD's Guidance for Undertaking Reviews in Health Care. 2008.

8. Moher D, Liberati A, Tetzlaff J, Altman DG. The PRISMA Group. Preferred reporting items for systematic reviews and meta-analyses: the PRISMA statement. PLoS Med. 2009; 6:e1000097. doi:10.1371/journal.pmed.1000097

9. Bondemark L, Holm A, Hansen K, et al. Long-term stability of orthodontic treatment and patient satisfaction. A systematic review. Angle Orthod. 2007;77:181-191.

10. Djeu G, Shelton C, Maganzini A. Outcome assessment of Invisalign and traditional orthodontic treatment compared with the American Board of Orthodontics objective grading system. Am J Orthod Dentofacial Orthop. 2005;128: 292-298.

11. Kassas W, Al-Jewair T, Preston CB, Tabbaa S. Assessment of Invisalign treatment outcomes using the ABO Model Grading System. J World FedOrthod. 2013;2:e61-e64.

12. Simon M, Keilig L, Schwarze J, Jung BA, Bourauel C. Treatment outcome and efficacy of an aligner techniqueregarding incisor torque, premolar derotation and molar distalization. BMC Oral Health. 2014;14:68.

13. Kravitz ND, Kusnoto B, Agran B, Viana G. Influence of attachments and interproximal reduction on the accuracy of canine rotation with Invisalign A prospective clinical study. Angle Orthod. 2008;78:682-687.

14. Kuncio D, Maganzini A, Shelton C, Freeman K. Invisalign and traditional orthodontic treatment postretention outcomes compared using the American Board of Orthodontics Objective Grading System. Angle Orthod. 2007;77:864-869.

15. Pavoni $C$, Lione R, Laganà G, Cozza $P$. Self-ligating versus Invisalign: analysis of dentoalveolar effects. Ann Stomatol (Roma). 2011;2:23-27.

16. Drake CT, McGorray SP, Dolce C, Nair M, Wheeler TT. Orthodontic Tooth Movement with Clear Aligners. International Scholarly Research Network - ISRN Dentistry Volume 2012, Article ID 657973, 7 pages, doi: 10.5402/ 2012/657973.

17. Clements KM, Bollen AM, Huang G, King G, Hujoel P, Ma T. Activation time and material stiffness of sequential removable orthodontic appliances. Part 2: dental improvements. Am J Orthod Dentofacial Orthop. 2003;124:502-508.

18. Baldwin DK, King G, Ramsay DS, Huang G, Bollen AM. Activation time and material stiffness of sequential removable orthodontic appliances. Part 3: premolar extraction patients. Am J Orthod Dentofacial Orthop. 2008;133: 837-845.

19. Burstone CR. Deep overbite correction by intrusion. Am J Orthod. 1977;72:1-22.

20. Weiland FJ, Bantleon HP, Droschl H. Evaluation of continuous arch and segmented arch leveling techniques in adult patients-a clinical study. Am J Orthod Dentofacial Orthop. 1996;110:647-652.

21. Greenlee GM, Huang GJ, Chen SS, Chen J, Koepsell T, Hujoel P. Stability of treatment for anterior open-bite malocclusion: a meta-analysis. Am J Orthod Dentofacial Orthop. 2011;139:154-169. doi: 10.1016/j.ajodo.2010.10.019 
22. Proffit WR, Fields HW Jr, Sarver DM. Contemporary Orthodontics. Elsevier Health Sciences; 2006.

23. Nguyen CV, Chen J. Chapter 14. In: Tuncay OC, ed. The Invisalign System. New Malden, UK: Quintessence Publishing Company, Ltd; 2006:12-32.

24. Krishnan V, Davidovitch Z. Cellular, molecular, and tissuelevel reactions to orthodontic force. Am J Orthod Dentofacial Orthop. 2006;129:469.e1-469.e32.
25. Cattaneo PM, Dalstra M, Melsen B. Strains in periodontal ligament and alveolar bone associated with orthodontic tooth movement analyzed by finite element. Orthod Craniofac Res. 2009;12:120-128.

26. Nakao K, Goto T, Gunjigake KK, Konoo T, Kobayashi S, Yamaguchi K. Intermittent force induces high RANKL expression in human periodontal ligament cells. J Dent Res. 2007;86:623-628. 